\title{
Sustainable conversion of agro-wastes into useful adsorbents
}

\author{
Olugbenga Solomon Bello ${ }^{1}$ Emmanuel Seun Owojuyigbe ${ }^{1} \cdot$ \\ Monsurat Abiodun Babatunde ${ }^{1} \cdot$ Folasayo Eunice Folaranmi $^{1}$
}

Received: 6 May 2016/Accepted: 11 October 2016/Published online: 5 November 2016

(c) The Author(s) 2016. This article is published with open access at Springerlink.com

\begin{abstract}
Preparation and characterization of raw and activated carbon derived from three different selected agricultural wastes: kola nut pod raw and activated (KNPR and KNPA), bean husk raw and activated (BHR and BHA) and coconut husk raw and activated (CHR and CHA) were investigated, respectively. Influences of carbonization and acid activation on the activated carbon were investigated using SEM, FTIR, EDX, $\mathrm{pH}_{\mathrm{pzc}}$ and Boehm titration techniques, respectively. Carbonization was done at $350{ }^{\circ} \mathrm{C}$ for $2 \mathrm{~h}$ followed by activation with $0.3 \mathrm{M} \mathrm{H}_{3} \mathrm{PO}_{4}$ (orthophosphoric acid). Results obtained from SEM, FTIR, and EDX revealed that, carbonization followed by acid activation had a significant influence on morphology and elemental composition of the samples. SEM showed welldeveloped pores on the surface of the precursors after acid treatment, FTIR spectra revealed reduction, broadening, disappearance or appearance of new peaks after acid activation. EDX results showed highest percentage of carbon by atom respectively in the order BHA $>$ KNPA $>$ CHA respectively. The $\mathrm{pH}_{\mathrm{pzc}}$ was found to be 5.32, 4.57 and 3.69 for KNPA, BHA and CHA, respectively. Boehm titration result compliments that of $\mathrm{pH}_{\mathrm{pzc}}$, indicating that the surfaces of the prepared adsorbents are predominantly acidic. This study promotes a sustainable innovative use of agrowastes in the production of cheap and readily available activated carbons, thereby ensuring more affordable water and effluent treatment adsorbents.
\end{abstract}

Olugbenga Solomon Bello

osbello06@gmail.com

1 Department of Pure and Applied Chemistry, LadokeAkintola University of Technology, Ogbomoso P. M. B. 4000, Oyo State, Nigeria
Keywords Activation · Adsorbent $\cdot$ Bean husk - Coconut husk $\cdot$ Kola nut pod

\section{Introduction}

Water is absolutely essential for sustenance of life, although millions of people worldwide are suffering from shortage of fresh and clean water. This is due to the rapid pace of industrialization, population expansion, and unplanned urbanization which have contributed largely to environmental pollution. Industries where textile, paper, rubber, plastics, paints and leather are manufactured discharge colored effluents into the environment, metals come from different sources like mining, metal cleaning, plating baths, pulp, paper and paper board mills, refineries and fertilizer industries (Tan et al. 2008; Jordi et al. 2009). The effluents discharged from these industries into water bodies have raised much concern because of potential health hazards associated with the entry of these toxic components into the food chain (Helen and Lima 2010). The presence of dyes, pigment and heavy metals in effluents from industries are some of the factors that lowers water quality, these pollutants are potential cause of adverse effects on health, increased environmental toxicity and poor aesthetic quality of water depending on the concentration of these pollutants in the environment (Jesus et al. 2011; Jafar and Shajudha 2012; Yadav et al. 2013).

The removal of these pollutants from sewage and industrial waste water has become a major issue worldwide due to their possible toxic effects. The conventional methods that are employed for the removal of heavy metals, dyes and pigments are found to be inefficient and expensive, especially when treating wastewater with low concentration of heavy metals. Some of these methods 
generate chemical or biological sludge which cannot be recovered or regenerated (Seetha et al. 2012; Dauda et al. 2010; Rao et al. 2009; Aydin et al. 2008; El-Ashtoukhy et al. 2008; Sud et al. 2008; Dabrowski et al. 2004; Zhen et al. 2002; Volesky and Leusch 1995).

According to Ahmad and Hameed (2010); El-Ashtoukhy et al. 2008; Gong et al. (2008), various methods have been employed for waste water treatment, activated carbon adsorption was found to be superior for wastewater treatment compared to other physical and chemical techniques, as they possess inherent limitations such as high cost, formation of hazardous by-products and intensive energy requirements, activated carbon has emerged as a potential alternative to conventional physiochemical technologies in waste-treatment facilities. Adsorption is an effective separation process that has advantages in terms of cost, flexibility, simplicity of design, and ease of operation compared to other techniques. It does not result in the formation of harmful substances (Rafatullah et al. 2010).

Wastes generated from agricultural sector are many, they constitute nuisance to the immediate environment where they are found, agricultural wastes are usually in large quantity, some of these wastes are known for their offensive odor, their decayed matter have the ability to alter soil $\mathrm{pH}$. Recently, different research works have been carried out, in other to prepare adsorbents from these agricultural wastes used as an alternative to commercially available activated carbon, which is expensive. Presently, agricultural waste materials have been proposed as economic and eco-friendly (Kumar and Kumar 2014). This will help in converting unwanted, surplus agricultural waste, of which billions of kilograms are produced annually, to value-added products (Vieira et al. 2009). These will protect the environment by getting rid of the danger that such waste can pose if left alone, most especially where disposal of agricultural wastes have become a major problem.

Adsorption process has proven to be one of the best water treatment technologies around the world, activated carbon is undoubtedly considered as a universal adsorbent for the removal of different types of pollutants from water (Ansari and Mohammad-Khah 2009; Bello et al. 2014). A number of agricultural waste materials have being studied for the removal of different pollutants from aqueous solutions at different operating conditions. They include: cassava peel (Horsfall et al. 2006), sugar beet pulp (Aksu and İşoğlu 2005), Nipha Palm (Wankasi et al. 2006), rice bran (Suzuki et al. 2007), coconut husk (Hameed et al, 2008; Tan et al, 2008), periwinkle shell (Bello et al. 2008), orange peel (Ningchuan et al. 2009), cocoa pod husk (Bello and Ahmad 2011), mango leaf (Khan et al. 2011), coconut shell (Bello and Ahmad 2012), loquat leaves (Akl and Salem 2012), durian seed (Bello et al. 2014), $\mathrm{TiO}_{2} / \mathrm{UV}$,
(Gupta et al. 2012), CNT/magnesium oxide composite (Saleh and Gupta 2012), fertilizer waste, (Gupta et al. 1998), waste material adsorbents (Mittal et al. 2011), waste material adsorbents (Mittal et al. 2009a), waste material adsorbents (Mittal et al. 2009b), waste material adsorbents (Gupta et al. 2010), tire derived carbons (Saleh and Gupta 2013), alumina-coated carbon nanotubes (Gupta et al. 2011), industrial wastes (Jain et al. 2003), Waste materials, (Mittal et al. 2010), Multi-walled carbon nanotubes-ionic liquid-carbon paste electrode (Khani et al. 2010), mesoporous activated carbon (Karthikeyan et al. 2012).

Activated carbons prepared from these precursors have been reported to be capable of removing metal ion and organic pollutant from aqueous solution. There are various types of dyes that are commonly used during dyeing processes such as basic dye, reactive dye, acidic dyes (Ahmad et al. 2014). These class of dyes differ in structural composition as well as in their interaction with adsorbent, the interaction is dictated by the nature of the adsorbent, such as morphology and the $\mathrm{pH}$ of the surface of adsorbent, this makes adsorbent to be effective towards adsorbate differently. Activated carbon materials are characterized by their large surface areas, high carbon content and better porosity which are well-developed. For these reasons, activated carbons are commercially used as adsorbents for the removal of organic chemicals and metal from the environment. Carbonaceous materials (animal, plant, or mineral origin) with high carbon content can be converted into activated carbon. This study examines the use of different agricultural waste materials as precursors for the preparation of cheap and readily available activated carbons.

\section{Materials and methods}

\section{Preparation of the adsorbent}

\section{Sample collection and preparation}

Kola nut pod, coconut husks were collected from dump sites while bean husk was obtained from Wazo market, Ogbomoso, Oyo State of Nigeria, where they were deposited. The samples were washed thoroughly with water to remove the dirt, the washed samples were then sun dried and pulverized.

\section{Modification of the sample}

Dried and pulverized samples were carbonized using muffle furnace, a carefully weighed $25.0 \pm 0.01 \mathrm{~g}$ of raw sample were put into a beaker containing $500 \mathrm{~cm}^{3}$ of $0.3 \mathrm{M}$ ortho-phosphoric acid $\left(\mathrm{H}_{3} \mathrm{PO}_{4}\right)$. The content of the beakers were thoroughly mixed and heated on a hot plate until a 
thick paste was formed. The paste of each samples were then transferred into a evaporating dish which was placed in a furnace and heated at $300{ }^{\circ} \mathrm{C}$ for $30 \mathrm{~min}$. Thereafter, the samples were allowed to cool and then washed with distilled water to a pH of $6.7 \pm 0.12$, oven dried at $105^{\circ} \mathrm{C}$ for $4 \mathrm{~h}$ and the adsorbents were stored in an air-tight container for further use.

\section{Characterization of adsorbents}

\section{Fourier transform infrared (FTIR)}

Fourier transform infrared (FTIR) spectroscopic analysis was used to study the surface chemistry of raw and activated carbon prepared from the selected samples using FTIR (FTIR-2000, Perkin Elmer). The FTIR spectra gave information about the characteristics functional groups on the surface of the sample.

\section{Scanning electron microscopy (SEM)}

The scanning electron microscope (SEM) is one of the most versatile instruments available for the examination and analysis of the microstructure morphology. The scanning electron microscopy (SEM) is a technique based on electron-material interactions, capable of producing images of the sample surface. This technique was used to study the morphological feature and surface characteristics of the selected materials.

\section{Energy dispersive X-ray (EDX)}

Elemental analyses were carried out using EDX, it determines the component elements present in the samples. Line spectra (peaks) are obtained, each corresponding to a particular element. The intensity of the characteristic lines is proportional to the concentration of the element.

\section{Determination of oxygen-containing functional groups}

The Boehm titration method was used for this analysis. According to the method used by Ekpete and Horsfall (2011), $1.0 \mathrm{~g}$ of the raw and the activated carbons were kept in contact with $15 \mathrm{ml}$ solution of $\mathrm{NaHCO}_{3}(0.1 \mathrm{M})$, $\mathrm{Na}_{2} \mathrm{CO}_{3}(0.05 \mathrm{M})$ and $\mathrm{NaOH}(0.1 \mathrm{M})$ for acidic group and $0.1 \mathrm{HCl}$ for basic group/site, respectively, at room temperature for more than 2 days. Subsequently, the aqueous solution was back titrated with $\mathrm{HCl}(0.1 \mathrm{M})$ for acid and $\mathrm{NaOH}(0.1 \mathrm{M})$ for basic groups. The number and type of acidic site were calculated by considering that $\mathrm{NaOH}$ neutralizes carboxylic, lactonic and phenolic groups, $\mathrm{Na}_{2-}$ $\mathrm{CO}_{3}$ neutralizes carboxylic and lactonic groups and that $\mathrm{NaHCO}_{3}$ neutralizes only carboxylic groups. The amount of oxygen containing functional groups, $F_{x}$, is calculated as follows:

$F_{x}=\frac{\left(V_{b x}-V_{e x}\right)}{m_{x}} \times M_{t} \times \mathrm{DF}$

$\mathrm{DF}=\frac{\text { initial volume }}{\text { selected volume for titration }}$,

where $F_{x}\left(\mathrm{mmolg}^{-1}\right)$ is the amount of oxygen-containing functional groups, $V_{b x}$ is the volume of titrant used to titrate the blank, $V_{e x}$ is the volume of the titrant used to titrate the extract, $M_{t}$ is the molarity of the titrant used and DF is the dilution factor.

\section{Determination of point of zero charge $\left(p H_{p z c}\right)$}

The $\mathrm{pH}$ point of zero charge determination $\left(\mathrm{pH}_{\mathrm{pzc}}\right)$ of the raw and activated carbons of the samples were carried out by adding $0.1 \mathrm{~g}$ of activated carbon to $200 \mathrm{ml}$ solution of $0.1 \mathrm{M} \mathrm{NaCl}$ whose initial $\mathrm{pH}$ has been measured and adjusted with $\mathrm{NaOH}$ or $\mathrm{HCl}$. The containers were sealed and placed on a shaker for $24 \mathrm{~h}$ after which the $\mathrm{pH}$ was measured. The $\mathrm{pH}_{\mathrm{pzc}}$ occurs when there is no change in the $\mathrm{pH}$ after contact with adsorbent.

\section{Results and discussion}

\section{Characterization of the prepared adsorbent}

\section{Fourier transform infrared spectral analysis}

Figure 1 shows the FTIR spectra of kola nut pod, bean husk and coconut husk, respectively. The spectra of the samples show the presence of several functional groups. These spectra revealed a reduction, broadening, disappearance or appearance of new peaks after the process of acid activation. The shifts in the spectra revealed the effect of activation on these adsorbents. The prominent bands after activation are indications that the prepared adsorbent will be effective in the removal of dyes and heavy metals (Bello et al. 2015). The FTIR spectra of kola nut pod (Fig. 1a), shows a broad band at $3773 \mathrm{~cm}^{-1}$ representing the $-\mathrm{OH}$ stretching of alcohol or phenol. A sharp band observed at $3433-3428 \mathrm{~cm}^{-1}$ represents the $-\mathrm{OH}$ bonding group of alcohol or carboxyl group. The peak around $2382-2371 \mathrm{~cm}^{-1}$ corresponds to $\mathrm{C} \equiv \mathrm{N}$ stretch vibration of amines. The band at $1856 \mathrm{~cm}^{-1}$ corresponds to $\mathrm{C}=\mathrm{O}$ stretching of acid halide and the peak observed at $1790 \mathrm{~cm}^{-1}$ was assigned to $\mathrm{C}=\mathrm{O}$ stretch of acid halide. The peak observed at $1640-1699 \mathrm{~cm}^{-1}$ represents $\mathrm{C}=\mathrm{C}$ stretch of alkenes. The one at $1414-1472 \mathrm{~cm}^{-1}$ corresponds to C$\mathrm{C}$ stretching vibration of aromatic. The band observed at 
Fig. 1 FTIR spectra of a KNPR, b KNPA, c BRH, d BRA, e CHR, f CHA
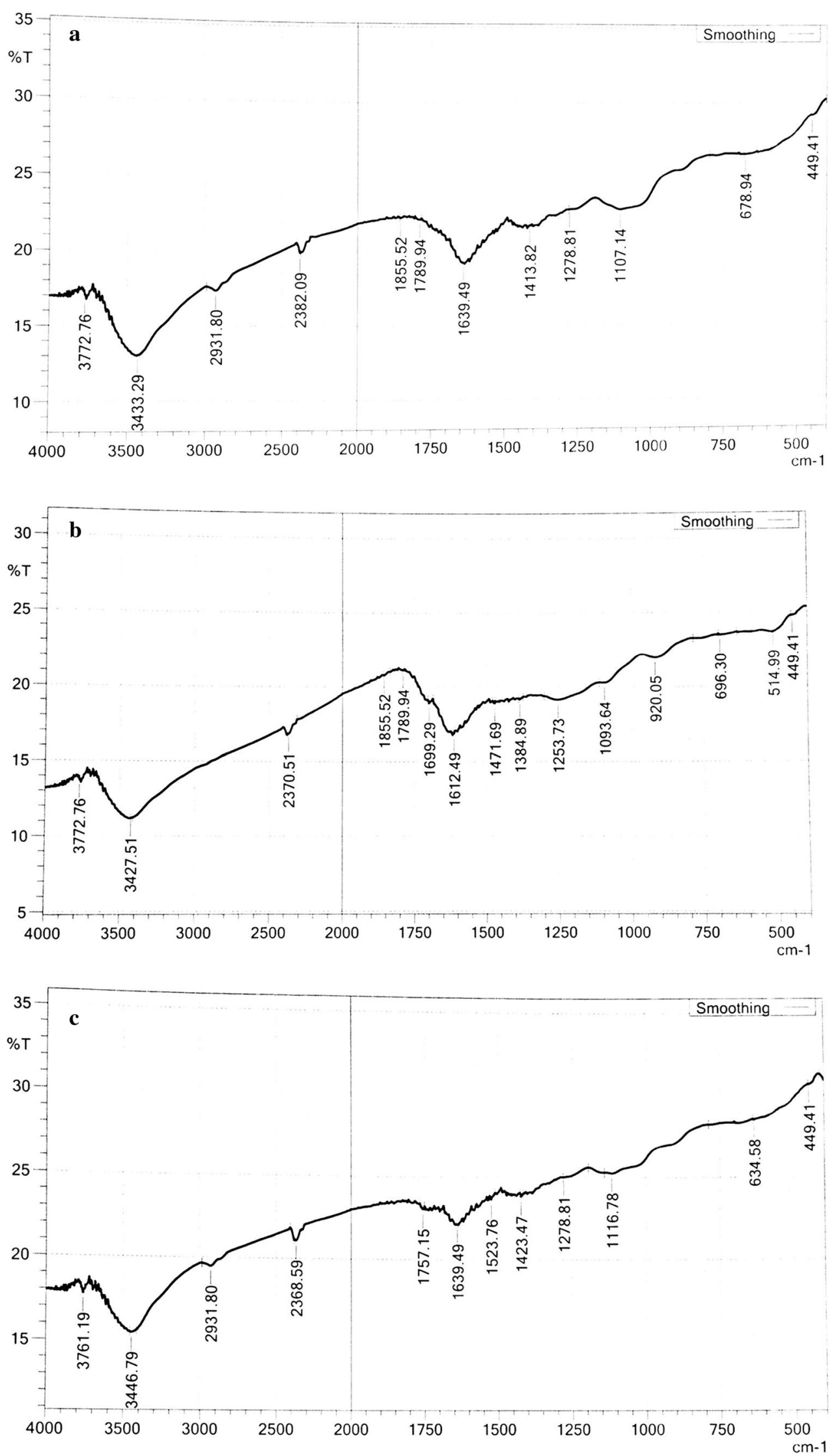
Fig. 1 continued
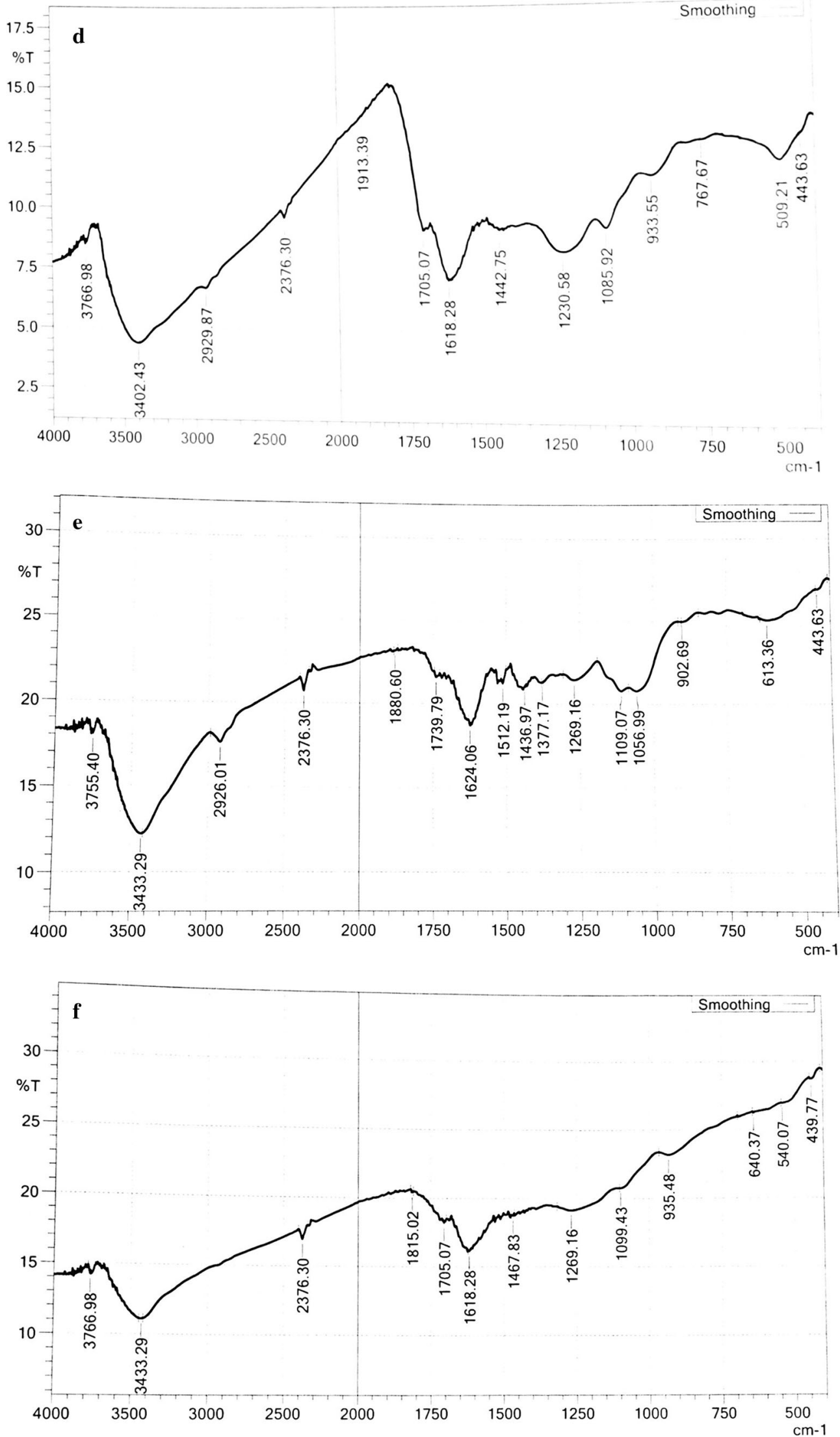
Fig. 2 SEM micrographs of kola nut pod raw and activated (KNPR and KNPA), bean husk raw and activated (BHR and BHA) and coconut husk raw and activated (CHR and CHA)
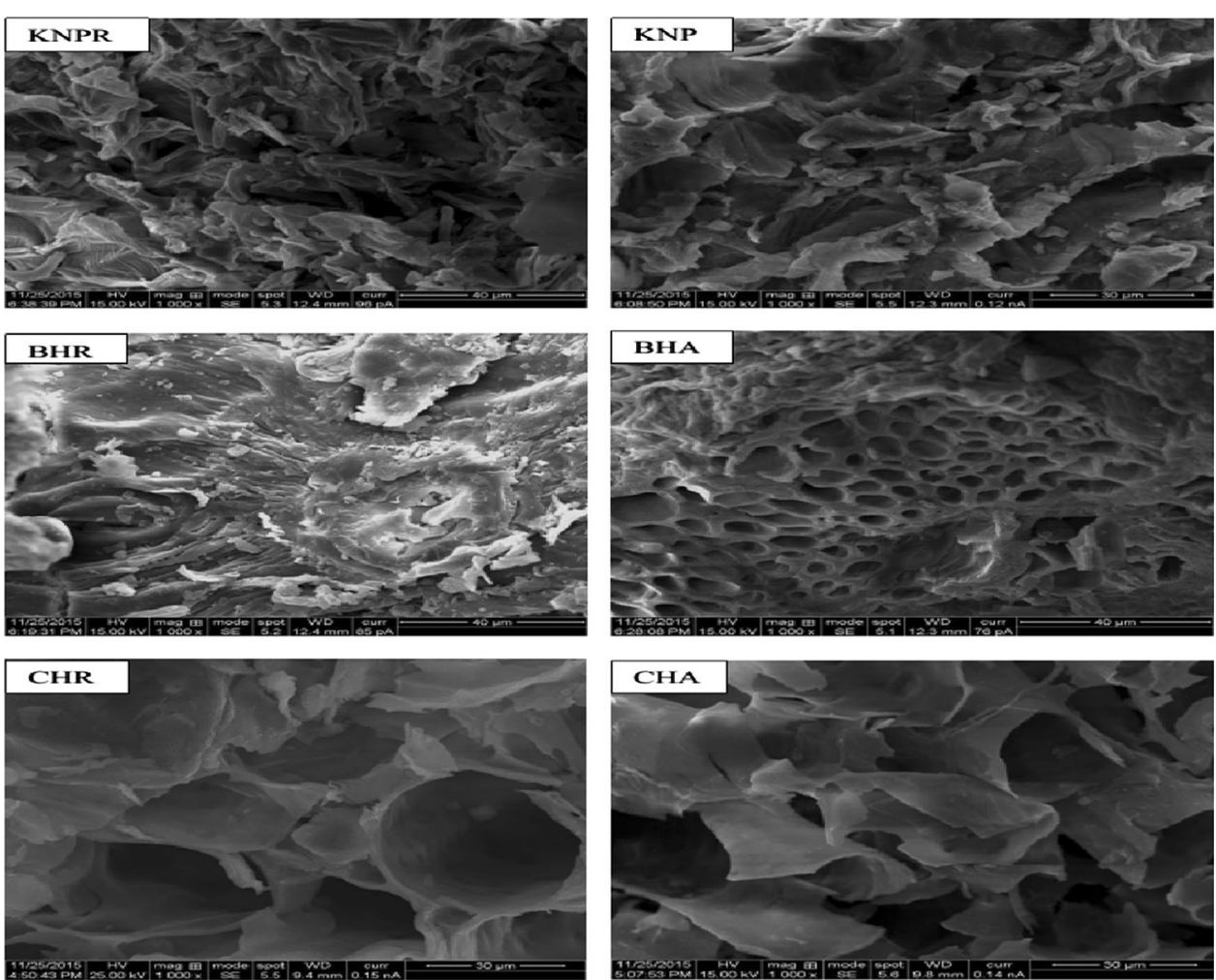

Table 1 EDX data of kola nut pod raw and activated (KNPR and KNPA), bean husk raw and activated (BHR and BHA) and coconut husk raw and activated (CHR and CHA)

\begin{tabular}{|c|c|c|c|c|c|c|}
\hline \multirow[t]{2}{*}{ Elements } & \multicolumn{2}{|c|}{ Atomic percentage (At.\%) } & \multicolumn{2}{|c|}{ Atomic percentage (At.\%) } & \multicolumn{2}{|c|}{ Atomic percentage (At.\%) } \\
\hline & KNPR & KNPA & BHR & BHA & CHR & CHA \\
\hline $\mathrm{C}$ & 67.76 & 88.54 & 84.21 & 89.02 & 83.70 & 87.13 \\
\hline $\mathrm{O}$ & 10.28 & 4.51 & 6.30 & 7.98 & 10.26 & 4.99 \\
\hline $\mathrm{Mg}$ & 2.78 & Nil & 0.85 & Nil & Nil & 0.10 \\
\hline $\mathrm{Mn}$ & 2.28 & Nil & Nil & Nil & Nil & Nil \\
\hline $\mathrm{Al}$ & Nil & Nil & 0.55 & 3.00 & 0.35 & 0.21 \\
\hline $\mathrm{Si}$ & Nil & Nil & 1.83 & Nil & 0.60 & Nil \\
\hline $\mathrm{Ca}$ & 3.81 & Nil & 0.53 & Nil & 0.53 & 1.96 \\
\hline $\mathrm{K}$ & 9.10 & 6.75 & 5.48 & Nil & 2.78 & Nil \\
\hline $\mathrm{Cl}$ & 2.16 & Nil & 0.76 & Nil & 1.79 & Nil \\
\hline $\mathrm{Fe}$ & 1.84 & Nil & Nil & Nil & Nil & Nil \\
\hline $\mathrm{P}$ & Nil & Nil & Nil & Nil & Nil & 5.61 \\
\hline Total & 100 & 100 & 100 & 100 & 100 & 100 \\
\hline
\end{tabular}

1279-1254 $\mathrm{cm}^{-1}$ corresponds to $\mathrm{C}-\mathrm{H}$ alkyl halide, $1107-1094 \mathrm{~cm}^{-1}$ were assigned to $\mathrm{C}-\mathrm{N}$ stretch of aliphatic amines. The band at $679-696 \mathrm{~cm}^{-1}$ corresponds to $\mathrm{C} \equiv \mathrm{C}$ bending of alkynes.

Also, Fig. 1b shows FTIR spectra of bean husk, a broad band observed at $3761 \mathrm{~cm}^{-1}$, represents bonded $\mathrm{OH}$ groups. The peak at $2930-2368 \mathrm{~cm}^{-1}$ shows an aliphatic $\mathrm{C}-\mathrm{H}$ stretching vibration. $1757-1639 \mathrm{~cm}^{-1}$ shows $\mathrm{C}=\mathrm{O}$ stretching of carboxylic group. The band observed at
$1523 \mathrm{~cm}^{-1}$ corresponds to the secondary amine group. The peak shown at $1423 \mathrm{~cm}^{-1}$ indicates an aromatic C-C stretch and $\mathrm{C}-\mathrm{O}$ stretch was observed at $1279 \mathrm{~cm}^{-1}$. The band around $1117 \mathrm{~cm}^{-1}$ shows presence of $\mathrm{C}=\mathrm{O}$ bonds of ether, ester or phenols. $\mathrm{O}-\mathrm{H}$ bending was observed at $633 \mathrm{~cm}^{-1}$.

Figure 1c is the FTIR spectra of coconut husk, the long bandwidth around $3433.29 \mathrm{~cm}^{-1}$ indicated that the main functional groups found on $\mathrm{CHR}$ and $\mathrm{CHA}$; O-H stretching 


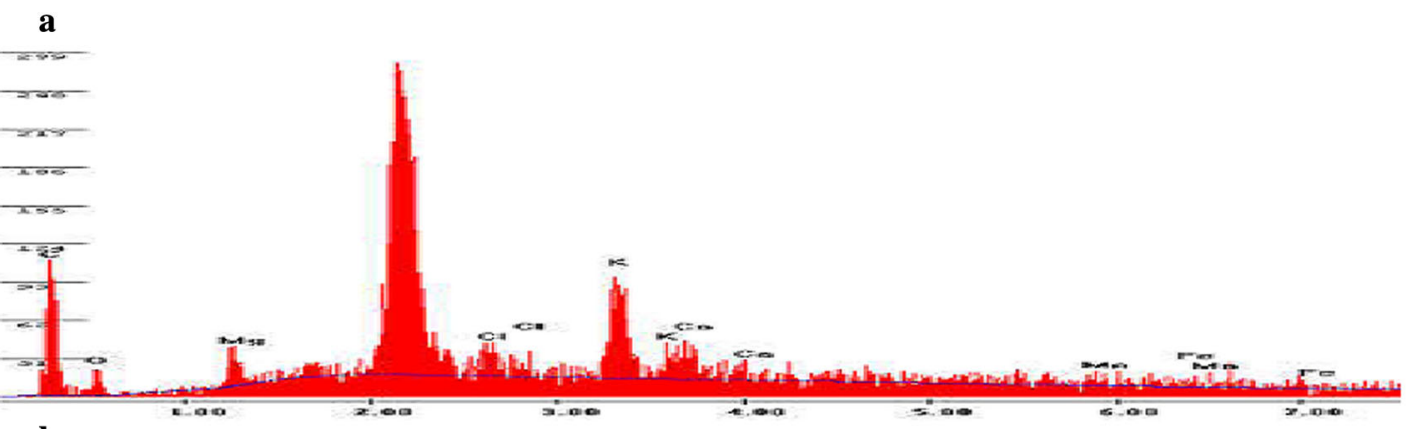

b
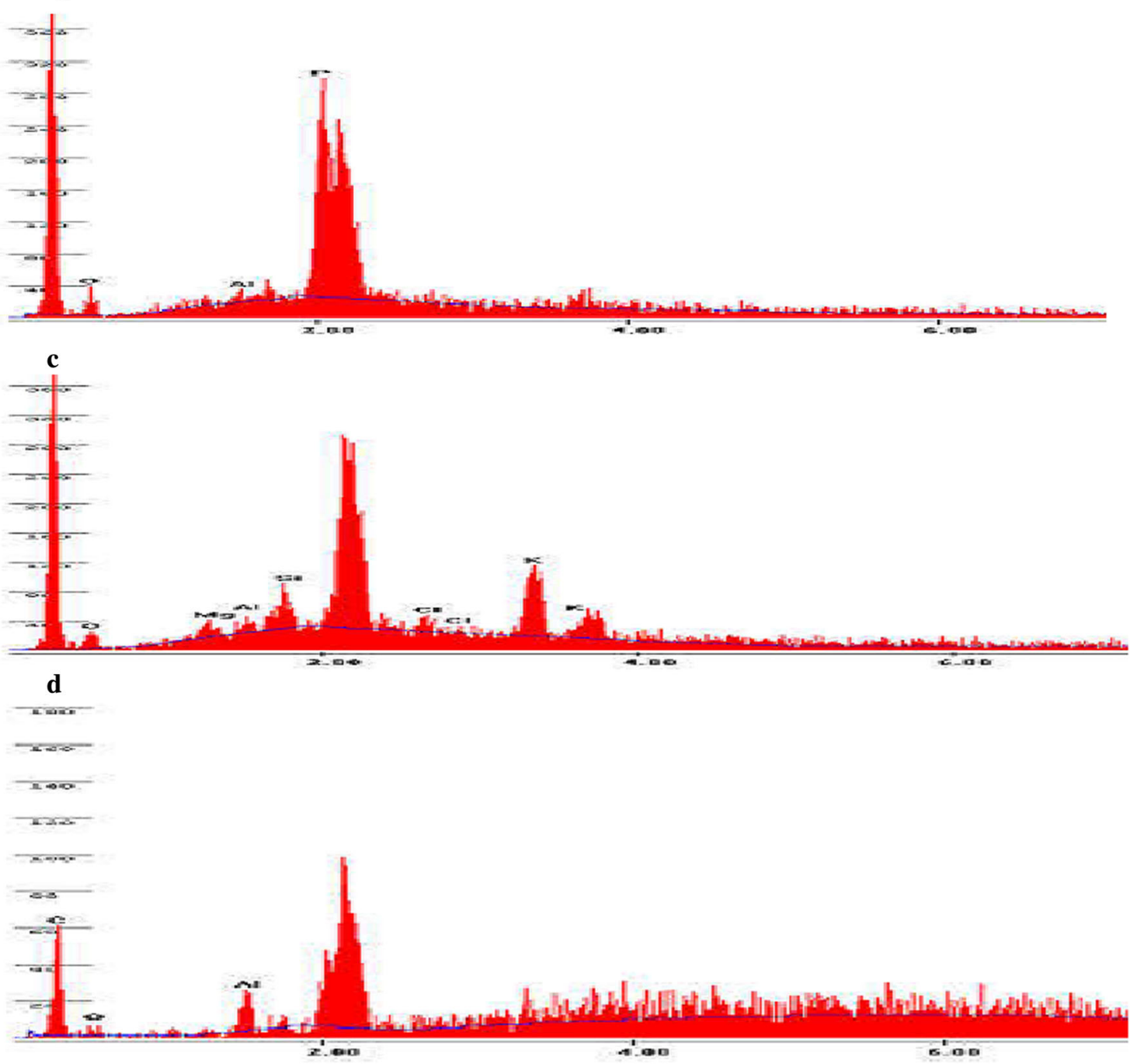

Fig. 3 Energy dispersve X-ray spectra of kola nut pod raw and activated (a KNPR, b KNPA), bean husk raw and activated (c BHR, d BHA) and coconut husk raw and activated (e CHR, $\mathbf{f}$ CHA)

vibration of hydroxyl functional groups including hydrogen bonding. The band observed at $2926.01 \mathrm{~cm}^{-1}$ was assigned to the aliphatic $\mathrm{C}-\mathrm{H}$ group. Other major peaks detected at bandwidths of $2376.30 \mathrm{~cm}^{-1}, \quad 1705-1739.79 \mathrm{~cm}^{-1}$,
$1624.06-1618.28 \mathrm{~cm}^{-1}$ and $1377.17 \mathrm{~cm}^{-1}$ were, respectively, attributed to $\mathrm{C} \equiv \mathrm{C}$ stretching of the alkyne group; vibration of carboxylic $\mathrm{C}=\mathrm{O}$ stretching of lactones, ketones, and carboxylic anhydrides; $\mathrm{C}=\mathrm{C}$ of aromatic ring; 

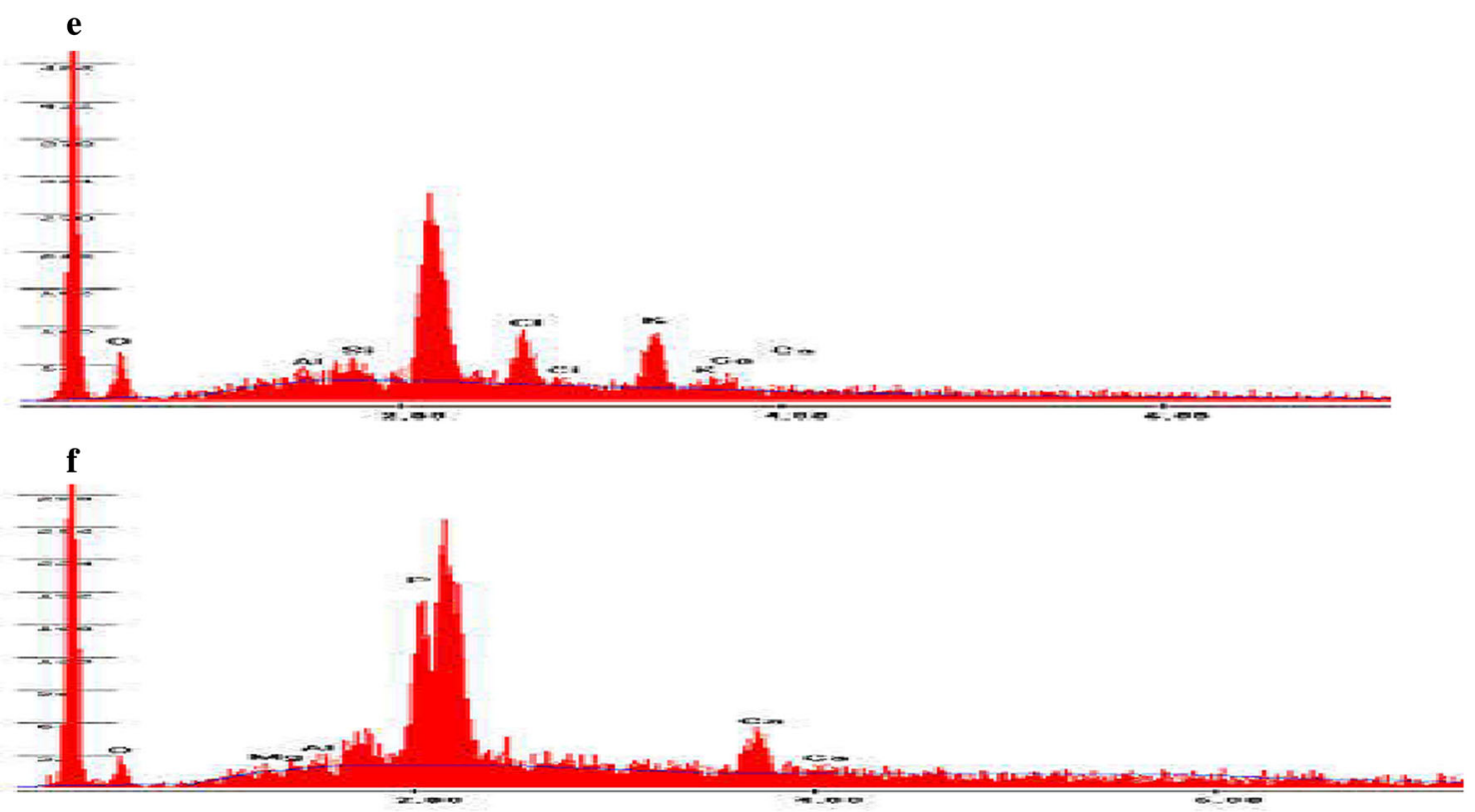

Fig. 3 continued

and $\mathrm{C}-\mathrm{H}$ stretching in alkanes or alkyl group. The disappearance of ether and phenol in the CHA sample shows that these functional groups are thermally unstable (Ahmad et al. 2014).

The changes observed in the FTIR spectra of the selected sample confirm the effect of acid activation on the raw samples; this is an indication that these samples will be a useful adsorbent in waste water treatment (Bello et al. 2015).

\section{Scanning electron micrograph (SEM)}

Scanning electron micrograph (SEM) of kola nut pod raw (KNPR), kola nut pod activated (KHPA), bean husk raw (BHR), bean husk activated (BHA) and coconut husk raw (CHR), coconut husk activated (CHA) are shown in Fig. 2, respectively. The surface morphology of the selected samples clearly shows that KHPR, BHR and CHR surface pores were not properly developed, rough and uneven, and there are several pores formed, and are distributed over surface of the precursor after acid treatment. This is an indication that $\mathrm{H}_{3} \mathrm{PO}_{4}$ was effective in creating well-developed pores on the surface of the precursor, thus, leading to activated carbon with large surface area and porous surface structure. This was due to the breakdown of the lignocellulosic materials at high temperature followed by the evaporation of volatile compounds leaving samples with well-developed pores. The availability of pores and internal surface is requisite for effective adsorbent (Rao et al. 2006; Bello et al. 2015). Thus, the porous nature of
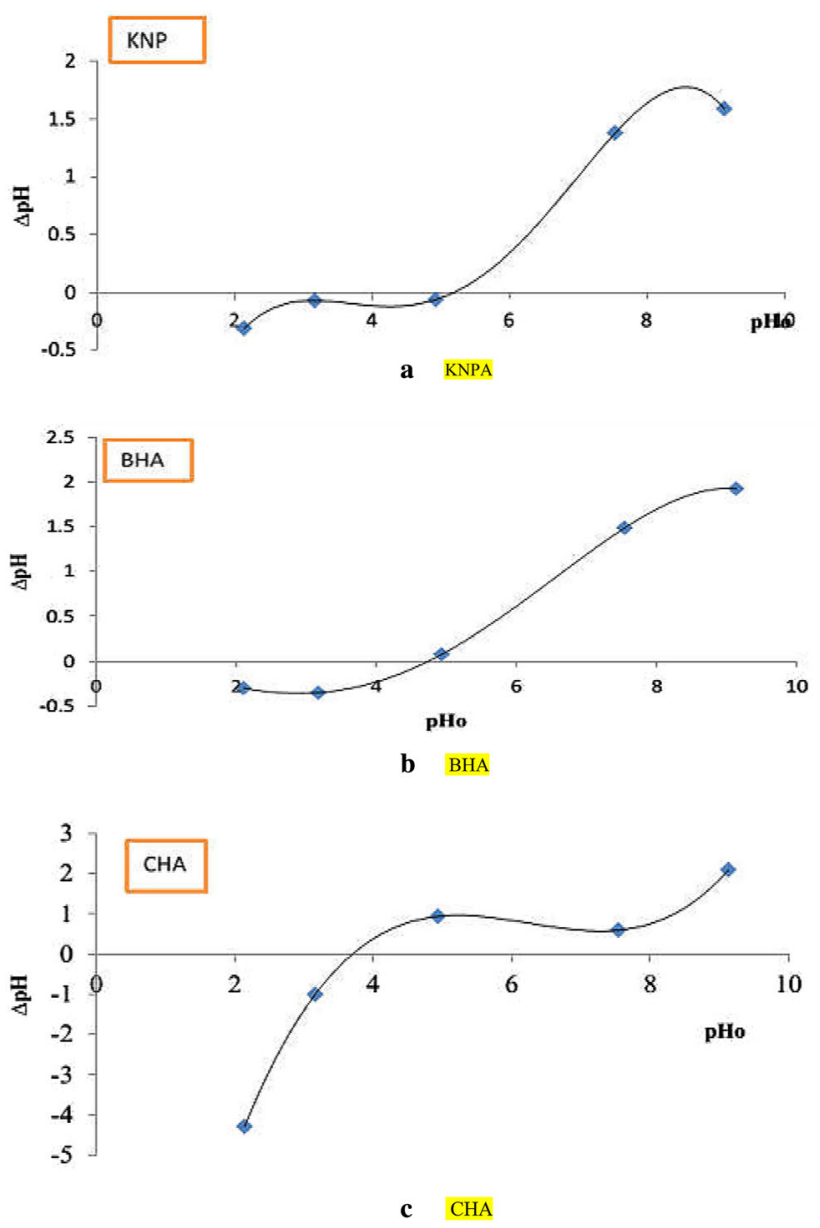

Fig. 4 Plot of pHpzc of a KNPA, b BHA and c CHA 
Table 2 Functional groups on kola nut pod activated (KNPA), bean husk activated (BHA) and coconut husk activated (CHA)

\begin{tabular}{|c|c|c|c|c|c|}
\hline Adsorbents & Carboxylic $\left(\mathrm{mmol} \mathrm{g}^{-1}\right)$ & Lactonic $\left(\mathrm{mmol} \mathrm{g}^{-1}\right)$ & Phenolic $\left(\mathrm{mmol} \mathrm{g}^{-1}\right)$ & Basic $\left(\mathrm{mmol} \mathrm{g}^{-1}\right)$ & Acidic $\left(\mathrm{mmol} \mathrm{g}^{-1}\right)$ \\
\hline KNPA & 0.1210 & 0.0154 & 0.000 & 0.0375 & 0.1364 \\
\hline BHA & 0.5310 & 0.8450 & 0.0210 & 0.7000 & 1.3970 \\
\hline CHA & 1.5210 & 0.3260 & 0.1872 & 0.096 & 2.0342 \\
\hline
\end{tabular}

the adsorbent prepared will help in adsorbent uptake which will be of help in adsorption process. These pores will provide a good surface for dye, heavy metals and other pollutant to be trapped and adsorbed onto (Bello et al. 2015; Ahmad et al. 2015a, b).

\section{Energy dispersive $X$-ray}

Elemental analyses of both raw and acid-activated samples were carried out using EDX to determine qualitatively and quantitatively the elements present in kola nut pod raw (KNPR), kola nut pod activated (KHPA), bean husk raw (BHR), bean husk activated (BHA) and coconut husk raw (CHR), coconut husk activated (CHA). The results obtained are shown in Table 1. Figure 3 shows the spectra of the results displayed in the Table 1 . It was observed that carbon has the highest percentage by weight when compared with other elements present in the samples. Also carbon content increased after acid activation showing the effectiveness of the acid treatment on the precursors. According to Xiong and coworkers only samples with high carbon content can be an efficient adsorbent for the removal of dye, heavy metals and other organic pollutant from aqueous solution (Xiong et al. 2013). Effectiveness of the prepared adsorbent based on the carbon content in the removal of pollutant is in the order $\mathrm{KNPA}>\mathrm{BHA}>\mathrm{CHA}$ (Table 1). Results show that the most effective adsorbent among those prepared is KNPA followed by BHA and CHA.

\section{Determination of $\mathrm{pH}$ point of zero charge}

$\mathrm{pH}$ point of zero charge of activated carbon prepared from these waste materials were determined, the values were known by determining the point where the resulting curve cut through the $\mathrm{pH}_{\mathrm{o}}$ axis as shown in Fig. 4. The $\mathrm{pH}_{\mathrm{pzc}}$ was found to be 5.32, 4.57 and $3.69 \mathrm{mmol} \mathrm{g}^{-1}$ for KNPA, BHA and CHA, respectively. The combined influence of all the functional groups of activated carbon determines $\mathrm{pH}_{\mathrm{pzc}}$, i.e., the $\mathrm{pH}$ at which the net surface charge on carbon was zero. At $\mathrm{pH}<\mathrm{pH}_{\mathrm{pzc}}$, the carbon surface has a net positive charge, while at $\mathrm{pH}>\mathrm{pH}_{\mathrm{pzc}}$ the surface has a net negative charge (Al-Degs et al. 2000). Cation adsorption becomes enhanced at higher than the pHpzc, while adsorption of anions is equally enhanced at $\mathrm{pH}$ less than $\mathrm{pHpzc}$
(Almeidal et al. 2009; Farahani et al. 2011). This is consistent with the value of Boehm titration, showing the dominance of acidic groups on the surface of the prepared adsorbents (Table 2).

\section{Determination of oxygen containing functional groups}

Boehm titration technique was used to characterize the surface chemical property of the absorbent. Table 2 shows the Boehm titration result. The dominance of acidic groups on the activated carbon prepared from the selected material is higher than the basic groups, suggesting that the functional groups on the adsorbent surface are predominantly acidic. Higher acidic groups suggests more oxygenated functional groups, resulting in increase in adsorption capacity (Farahani et al. 2011).

\section{Conclusion}

This study revealed that the activated carbon prepared from selected agricultural wastes after acid activation and carbonization was effective in creating well-developed pores on the surface of the precursor, yielding product with high carbon content. Surface of the studied samples are acidic. These are indication that the activated carbon prepared from these selected agricultural wastes has promising ability, to remove different pollutants such as dye, metal ion and other organic pollutants. These adsorbents can be considered as suitable alternative precursors in lieu of the expensive commercial activated carbon. Moreover, since they are sourced locally, their sustained availability is guaranteed.

Acknowledgements The corresponding author acknowledges the support obtained from The World Academy of Science (TWAS) in form of Grants; Research Grant Numbers: 11-249 RG/CHE/AF/ AC_1_ UNESCO FR: 3240262674 (2012) and 15-181 RG/CHE/AF/ AC_1_: 3240287083 (2015).

Open Access This article is distributed under the terms of the Creative Commons Attribution 4.0 International License (http:// creativecommons.org/licenses/by/4.0/), which permits unrestricted use, distribution, and reproduction in any medium, provided you give appropriate credit to the original author(s) and the source, provide a link to the Creative Commons license, and indicate if changes were made. 


\section{References}

Ahmad AA, Hameed BH (2010) Fixed-bed adsorption of reactive azo dye onto granular activated carbon prepared from waste. J Hazard Mater 175:298-303

Ahmad MA, Ahmad N, Bello OS (2014) Adsorptive removal of malachite green dye using durian seed-based activated carbon. Water Air Soil Pollut 225(8):1-18

Ahmad MA, Ahmad N, Bello OS (2015a) Removal of remazol brilliant blue reactive dye from aqueous solutions using watermelon rinds as adsorbent. J Disp Sci Technol 36(6):845-858

Ahmad MA, Afandi NS, Adegoke KA, Bello OS (2015b) Optimization and batch studies on adsorption of malachite green dye using rambutan seed activated carbon. Desalination Water Treat. doi:10.1080/19443994.2015.1119744

Akl MA, Salem NM (2012) Biosorption of copper(II) and lead(II) ions from aqueous solutions by modified loquat (Eriobotrya japonica) leaves (MLL). J Chem Eng Mater Sci 3(1):7-17

Aksu Z, İşoğlu A (2005) Removal of copper (II) ions from aqueous solution by biosorption onto agricultural waste sugar beet pulp. Proc Biochem 40:3031-3044

Al-Degs Y, Khraisheh M, Allen S, Ahmad M (2000) Effect of carbon surface chemistry on the reactive dyes from textile effluents. Water Res 34:927-935

Almeidal CAP, Debacher NA, Downs AJ, Cottet LC, Mello AD (2009) Removal of methylene blue from colored effluents by adsorption on montmorillonite clay. J Colloid Interface Sci $332: 46-53$

Ansari R, Mohammad-Khah A (2009) Activated charcoal: preparation, characterization and applications: a review article. Int $\mathrm{J}$ Chem Tech Res 1(4):859-864

Aydin H, Bulut Y, Yerlikaya C (2008) Removal of $\mathrm{Cu}$ (II) ion from aqueous solution by adsorption onto low-cost adsorbents. J Environ Manage 87(1):37-45

Bello OS, Ahmad MA (2011) Adsorptive removal of a synthetic textile dye using coca pod husks. Toxicol Environ Chem 93(7):1298-1308

Bello OS, Ahmad MA (2012) Coconut (Cocos nucifera) shell based activated carbon for the removal of malachite green dye from aqueous solutions. Sep Sci Technol 47(6):903-912

Bello OS, Adeogun AI, Ajaelu JC, Fehintola EO (2008) Adsorption of methylene blue onto activated carbon derived from periwinkle shells: kinetics and equilibrium studies. Chem Ecol 24(4):285-295

Bello OS, Adegoke KA, Bello OU, Lateef IO (2014) Sequestering Nikel (II) Ions from aqueous solution using various adsorbents: a review. Pak J Anal Environ 15(1):1-17

Bello OS, Adegoke KA, Akinyunni OO (2015) Preparation and characterization of a novel adsorbent from Moringa oleifera leaf. Appl Water Sci. doi:10.1007/s13201-015-0345-4

Dabrowski A, Hubicki Z, Podkoscielny P, Robens E (2004) Selective removal of the heavy metal ions from waters and industrial wastewaters by ion-exchange method. Chemosphere 56(2):91-106

Dauda BEN, Egila JN, Jimoh T (2010) Biosorptive removal of cobalt (II) ions from aqueous solution by Amaranthus hydridus $L$ stalk wastes. Afr J Biotechnol 48(9):8192-8198

Ekpete OA, Horsfall MJ (2011) Preparation and characterization of activated carbon derived from fluted pumpkin stem waste (Telfairia occidentalis Hook F). Res J Chem Sci 1(3):10-17

El-Ashtoukhy ESZ, Amin NK, Abdelwahab O (2008) Removal of lead (II) and copper (II) from aqueous solution using pomegranate peel as a new adsorbent. Desalination 223(1):162-173
Farahani M, Abdullah S, Hosseini S, Shojaeipour S, Kasisaz M (2011) Adsorption-based cationic dyes using the carbon active sugarcane bagasse. Proc Environ Sci 10:203-208

Gong R, Zhu S, Zhang D, Chen J, Ni S, Guan R (2008) Adsorption behavior of cationic dyes on citric acid esterifying wheat straw: kinetic and thermodynamic profile. Desalination 230:220-228

Gupta VK, Srivastava SK, Mohan D, Sharma S (1998) Design parameters for fixed bed reactors of activated carbon developed from fertilizer waste for the removal of some heavy metal ions. Waste Manage 17(8):517-522

Gupta VK, Mittal A, Mittal J, Malviya A, Dipika Kaur D (2010) Decoloration treatment of a hazardous triarylmethane dye, Light Green SF (Yellowish) by waste material adsorbents. J Colloid Interf Sci 342(2):518-527

Gupta VK, Agarwal S, Saleh TA (2011) Synthesis and characterization of alumina-coated carbon nanotubes and their application for lead removal. J Hazardous Mater 185(1):17-23

Gupta VK, Jain R, Mittal A, Saleh TA, Nayak A, Agarwal S, Sikarwar S (2012) Photo-catalytic degradation of toxic dye amaranth on $\mathrm{TiO}_{2} / \mathrm{UV}$ in aqueous suspensions. Mater Sci Eng C 32(1):12-17

Hameed BH, Tan IAW, Ahmad AL (2008) Adsorption isotherm, kinetic modeling and mechanism of 2,4,6-trichlorophenol on coconut husk-based activated carbon. Chem Eng 144(2):235-244

Helen KM, Lima RM (2010) Comparison of copper adsorption from aqueous solution using modified and unmodified hevea brasiliensis saw dust. Desalination 255:165-174

Horsfall MJ, Abia AA, Spiff AI (2006) Kinetic studies on the adsorption of $\mathrm{Cd}^{2+}, \mathrm{Cu}^{2+}$ and $\mathrm{Zn}^{2+}$ ions from aqueous solution by cassava (Manihot esculenta cranz) tuber bark waste. Bioresour Technol 97:283-291

Jafar AA, Shajudha BA (2012) Adsorption of copper from aqueous solution using low-cost adsorbent. Arch Appl Sci Res 4(3):1532-1539

Jain AK, Gupta VK, Bhatnagar A Suhas (2003) A comparative study of adsorbents prepared from industrial wastes for removal of dyes. Sep Sci Technol 38(2):463-481

Jesus AMD, Romão LPC, Araújo BR, Costa AS, Marques JJ (2011) Use of humin as an alternative material for adsorption/desorption of reactive dye. Desalination 274:13-21

Jordi L, Josep S, Joan L (2009) Modeling of the dynamic adsorption of an anionic dye through ion-exchange membrane adsorber. J Membr Sci 340:234-240

Karthikeyan S, Gupta VK, Boopathy R, Titus A, Sekaran G (2012) A new approach for the degradation of aniline by mesoporous activated carbon as a heterogeneous catalyst: kinetic and spectroscopic studies. J Mol Liquids 173(2012):153-163

Khan TA, Sharma S, Ali I (2011) Adsorption of rhodamine b dye from aqueous solution onto acid activated mango (Magnifera indica) leaf powder: equilibrium, kinetic and thermodynamic studies. J Toxicol Environ Health Sci 3(10):286-297

Khani H, Rofouei MK, Arab P, Gupta VK, Vafaei Z (2010) Multiwalled carbon nanotubes-ionic liquid-carbon paste electrode as a super selectivity sensor: Application to potentiometric monitoring of mercury ion (II). J Hazard Mater 183:402-409

Kumar B, Kumar U (2014) Removal of malachite green and crystal violet dyes from aqueous solution with bio-materials: a review. Glo J Res Eng 14(4):51-60

Mittal A, Kaur D, Malviya A, Mittal J, Gupta VK (2009a) Adsorption studies on the removal of coloring agent phenol red from wastewater using waste materials as adsorbents. J Colloid Interf Sci 337(2):345-354

Mittal A, Mittal J, Malviya A, Gupta VK (2009b) Adsorptive removal of hazardous anionic dye "Congo red" from wastewater using 
waste materials and recovery by desorption. J Colloid Interf Sci 340(1):16-26

Mittal A, Mittal J, Malviya A, Gupta VK (2010) Removal and recovery of Chrysoidine $\mathrm{Y}$ from aqueous solutions by waste materials. J Colloid Interf Sci 344(2):497-507

Ningchuan F, Xueyi G, Sha L (2009) Adsorption study of copper (II) by chemically modified orange peel. J Hazard Mater 164(2):1286-1292

Rafatullah M, Sulaiman O, Hashim R, Ahmad A (2010) Adsorption of methylene blue on low-cost adsorbents: a review. J Hazard Mater 177(1):70-80

Rao MM, Ramesh A, Purna CR, Seshaiah K (2006) Removal of copper and cadmium from the aqueous solution by activated carbon derived from Ceiba pentandra hulls. J Hazard Mater 129:123-129

Rao MM, Reddy DH, Venkateswarlu P, Seshaiah K (2009) Removal of mercury from aqueoususing activated carbon prepared from agricultural by-product/waste. J Environ Manage 90(1):634-643

Saleh TA, Gupta VK (2012) Column with CNT/magnesium oxide composite for lead(II) removal from water. Environ Sci Pollut Res 19:1224-1228

Saleh TA, Gupta VK (2013) Processing methods, characteristics and adsorption behavior of tire derived carbons: a review Adv. Colloid Interf Sci 211:93-101

Seetha RR, Nageswara RV, Rajendra PP, Chitti BN (2012) Sorption of lead (II) Ion from wastewater using carica papaya leaf powder. Int J Eng Sci Adv Technol 2(6):1577-1581

Sud D, Garima M, Kumar MP (2008) Agricultural waste material as potential adsorbent for sequestering heavy metal ions from aqueous solutions-a review. Bioresour Technol 99(14):6017-6027
Suzuki RM, Andrade AD, Sousa JC, Rollemberg MC (2007) Preparation and characterization of activated carbon from rice bran. Bioresour Technol 98(10):1986-1991

Tan IA, Ahmad AL, Hameed BH (2008) Adsorption of basic dye on high-surface -area activated carbon prepared from coconut husk: equilibrium, kinetic and thermodynamic studies. J Hazard Mater 154:337-347

Vieira AP, Santana SAA, Bezerra CWB, Silva HAS, Chaves JAP, Melo JCP, Filho Edson CS, Airoldi C (2009) Kinetics and thermodynamics of textile dye adsorption from aqueous solutions using babassu coconut mesocarp. J Hazard Mater 166:1272-1278

Volesky B, Leusch A (1995) The influence of film diffusion on cadmium biosorption by marine biomass. J Biotechnol 43:1-10

Wankasi D, Horsfall MJ, Spiff AI (2006) Sorption kinectics of Pb(II) and $\mathrm{Cu}(\mathrm{II})$ ion from aqueous solution by Nipah Palm (Nypafrutie answurmb) shoot biomass. Electron J Biotechnol 9:1-7

Xiong C, Jila Q, Chen X, Wang G, Yao C (2013) Optimization of polyacrylonitrile-2-aminothiazole resin synthesis, characterization, and its adsorption performance and mechanism for removal of $\mathrm{Hg}$ (II) from aqueous solution. Ind Eng Chem Res 52:4978-4986

Yadav SK, Sinha S, Singh DK (2013) Removal of Lead (II) from aqueous solution using papaya seed carbon: characteristics and kinetics study. Int J Civil Environ Eng 4(2):127-136

Zhen GS, Xian DL, Chun CW, Huai MC, Hong C (2002) Lead, phyto extraction from contaminated soil with high biomass plant species. J Environ Qual 31(6):1893-1900 